\title{
O tópico retomado na posição de sujeito: diferenças entre português brasileiro e português europeu
}

\section{Topic resumed in subject position: differences between Brazilian Portuguese and European Portuguese}

\author{
Sheltom de Aragão* \\ Universidade Federal da Babia \\ Salvador, Bahia, Brasil \\ Edivalda Araújo** \\ Universidade Federal da Babia \\ Salvador, Bahia, Brasil
}

\begin{abstract}
Resumo: O presente artigo tem como objetivo esclarecer diferenças entre o Português Brasileiro (PB) e o Português Europeu (PE) quanto aos mecanismos que regem a retomada do tópico em posição de sujeito. Tivemos como base teórica os pressupostos do Programa Minimalista da Teoria Gerativa (CHOMSKY, 1995, 1999, 2001). Após levantamento de dados reais de fala, analisamos as ocorrências à luz de trabalhos como os de Duarte (1993, 1995); Kato, Duarte, Cyrino e Berlinck (2006); Barbosa (1995, 2006); e Costa (2010, 2012). Em seguida, investigamos que propriedades morfossintáticas e/ou semânticas poderiam regular as diferenças encontradas. Os dados da análise foram extraídos de duas fontes para a década de 1970: o livro de inquéritos transcritos do Projeto Norma Urbana Culta (NURC) e os inquéritos disponibilizados online pela Universidade de Lisboa através do Centro de Referência do Português Contemporâneo (CRPC). Para a década de 2010, os corpora foram constituídos a partir de entrevistas concedidas por falantes brasileiros e portugueses a telejornais de suas respectivas regiões. Com este trabalho, concluímos que, conforme defendido por Costa (2010), as diferenças encontradas para a retomada de tópico em posição de sujeito decorrem de propriedades flexionais de cada variedade, não de condições discursivas, como defendido por outros autores.
\end{abstract}

Palavras-chave: Tópico. Sujeito. Sintaxe. Português Europeu. Português Brasileiro.

\begin{abstract}
This study aims to clarify differences between the Brazilian Portuguese (BP) and the European Portuguese (EP) in relation to the mechanisms that govern the resumption of the topic in a subject position. The theoretical base was the assumptions of The Minimalist Program (CHOMSKY, 1995, 1999, 2001). After a real speech data survey, the occurrences were analyzed in the light of works such as Duarte (1993, 1995)); Kato, Duarte, Cyrino e Berlinck (2006); Barbosa (1995, 2006); e Costa (2010, 2012). Subsequently, it was investigated which semantics and or morphosyntax properties could regulate the found differences. The analysis' data were extracted from two sources for the decade of 1970: the book of surveys transcript from the Linguistic Urban Cultured Norm Project (NURC) and the surveys made available online by the University of Lisbon through the Portuguese Contemporary Reference Center (CRPC). For the decade of 2010, the corpora were constituted from interviews granted by speakers from Brazil and Portugal to television programs of their respective regions. Through this paper, the reached conclusion, as advocated by Costa (2010), was that differences found to the topic's resumption in subject position results from flexural properties of each variation, not from discursive conditions, as advocated for some authors.
\end{abstract}

Keywords: Topic. Subject. Synthax. European Portuguese. Brazilian Portuguese.

* Mestre em Língua e Cultura (UFBA).E-mail: sheltomdearagao@gmail.com.

**Doutra em Linguística, professora da UFBA. E-mail: edivalda.araujo@gmail.com. 


\section{INTRODUÇÃO}

Neste artigo, analisaremos as ocorrências de tópicos com retomadas na posição de sujeito. Consideraremos o preenchimento ou não do sujeito no PB e no PE e discutiremos as posições que podem abrigar esses sintagmas nas estruturas sintáticas de cada variedade. Além disso, avaliaremos as relações sintáticas e semânticas (relativas ao traço de animacidade) estabelecidas entre o sujeito e o tópico.

Para realizar o estudo que aqui se apresenta, comparamos ocorrências encontradas em corpora do PB e do PE em duas décadas (1970 e 2010), constatamos os tipos de construções que aproximam e que distanciam as duas variedades da língua e buscamos compreender as possibilidades de configuração sintática de cada uma na estrutura subjacente à frase. Destacou-se em nossa pesquisa um tipo de construção muito frequente nas duas línguas, o Tópico Pendente com Retomada (TPR), sendo esta retomada o sujeito da oração. Assim, centramos a discussão nas relações entre sujeito e tópico que se revelam a partir das TPR tanto no PB quanto no PE.

Os resultados da análise empreendida mostram que as propriedades flexionais de cada variedade têm regulado padrões diferentes de concordância. Isso pode se refletir em construções de TPR com características peculiares no Brasil e em Portugal.

\section{O TÓPICO E AS CONSTRUÇÕES DE TPR}

Dedicamos esta seção à caracterização e a algumas reflexões teóricas sobre o tópico. Nossa análise teve como referência o clássico livro de Pontes (1987) e a tese de Araújo (2006), que descreve a dinâmica do tópico enquanto elemento sintático e discursivo simultaneamente. Obras diretamente relacionadas a essas ou que lhes deram subsídios teóricos também foram consideradas como suporte de análise e definição.

\subsection{O Tópico enquanto elemento semântico-discursivo}

As pesquisas sobre as Construções de Tópico (CT) no Português Brasileiro (PB) têm seu início marcado pelo trabalho de Eunice Pontes (1987), no qual se descrevem e analisam as produções de tópico por ela encontradas na fala dos brasileiros. Pontes (1987) traz esclarecimentos quanto à identificação do tópico, bem como explora o seu funcionamento nas sentenças do PB. Em concordância com Li e Thompson (1976) e Chafe (1976), a autora apresenta a definição para tópico, em uma perspectiva discursiva, como um quadro de referência para uma enunciação que será feita em seguida, o que se pode observar em um exemplo retirado do texto:

(1) "Essa bolsa, as coisas somem aqui dentro" (PONTES, 1987. Grifo nosso.)

Percebemos a presença de uma oração completa, "as coisas somem aqui dentro" e mais um elemento, em posição inicial - "Essa bolsa" -, criando este o quadro de referência, aquilo sobre o que se fala, em relação ao enunciado que aparece a seguir. $\mathrm{O}$ 
elemento "Essa bolsa", por se constituir como algo sobre o que se fala, como um quadro de referência, pode figurar discursivamente como tópico, conforme Pontes (1987). Não se pode esquecer ainda que o tópico, por/para funcionar como quadro de referência, precisa ser de conhecimento partilhado entre os interlocutores, mesmo que esta partilha não seja verbalizada, como provavelmente aconteceu no caso de "essa bolsa". A frase não faria sentido para o ouvinte se a bolsa não fosse do conhecimento de ambos ou somente do falante, seja por ter sido inserida como referente identificável na conversa anteriormente, seja pelo fato de figurar no contexto situacional no momento da enunciação. Uma vez que o elemento "essa bolsa" atende às especificidades aqui trazidas com base em Pontes (1987), podemos dizer que ele é discursivamente classificado como tópico.

A partir de Lambrecht (1996), Araújo (2006) analisa a conceituação do tópico sob o prisma discursivo e sintático, considerando suas características semântico-pragmáticas e funcionais e estabelecendo a relação entre a estrutura da informação e a estrutura gramatical. Assim, Araújo (2006) mostra como se dão as influências entre estas estruturas e qual é o reflexo desta interação na ordem dos constituintes da sentença.

A autora fala sobre "O caráter de 'ser sobre" com as noções sintáticas e discursivas do tópico, não sendo ele apenas um elemento deslocado, ou externo à oração, mas também uma referência sobre o que trata a oração/comentário. O tópico é, portanto, uma espécie de "guia", do ponto de vista discursivo, que, por ter importe semânticopragmático, é colocado pela sintaxe na periferia esquerda da sentença.

Quanto à estrutura da informação, Araújo (2006) reflete sobre a oposição entre informação "dada" e informação "nova". A informação dada constitui o conhecimento partilhado pelos interlocutores. A informação nova é detida por apenas um deles no momento da comunicação - o falante/escritor. Sempre é do falante/escritor que parte a noção de informação nova ou dada, ou seja, é ele quem faz a pressuposição sobre o conhecimento ou não do seu interlocutor em relação ao que vai ser falado/escrito. Apesar de o conceito ser simples e relativamente estável, a terminologia varia entre as seguintes opções de acordo com o modelo teórico: tema/rema, tópico/comentário, tópico/foco, e foco/background .

\subsection{O Tópico enquanto elemento sintático}

De acordo com o que explicitamos na sub-seção anterior, o tópico se define discursivamente como um quadro de referência para algo que vai ser dito. Foi apontado também que, do ponto de vista da estrutura da informação, o tópico carrega conhecimentos compartilhados entre os interlocutores, enquanto o comentário é constituído por uma informação nova para o ouvinte/leitor, geralmente chamada de foco. Quanto à sintaxe, entretanto, a definição do tópico obedece a outros critérios, dos quais tratamos nesta seção, como o fato de ser um elemento sintático deslocado à esquerda da frase, não obrigatoriamente selecionado pelo verbo.

${ }^{1}$ Para mais informações, consultar a tese de Araujo (2006), no site prohpor.org. 
O texto de Pontes (1987) fornece as primeiras bases para o entendimento acerca do tópico quanto ao seu caráter discursivo e traz importantes considerações a respeito dos aspectos sintáticos desse elemento no PB. A partir desse estudo, outros foram desenvolvidos sob a perspectiva sintática, como os de Mary Kato e Charllotte Galves, entre o final dos anos 80 e início dos 90. Acrescentando-se a essas análises, Araújo (2006) discute a dupla perspectiva do tópico (discursiva e sintática), possibilitando uma visão mais ampla sobre o fenômeno a partir das observações feitas por Lambrecht (1996), que estabelece a relação entre a estrutura da informação e a estrutura gramatical, na intenção de entender como se dão as influências entre elas e qual é o reflexo dessa interação na ordem dos constituintes da sentença.

Araújo (2009, p. 232) considera o tópico como "um sintagma nominal, lexical ou pronominal que se realiza numa posição geralmente deslocada à esquerda, [...] em torno do qual é construído um predicado ou comentário”. Com base na definição da autora, podemos analisar o exemplo em (2) e atestar que só o SN "O pneu” enquadra-se no que se entende por tópico, já que se posiciona perifericamente e estabelece referência para um comentário posterior, conforme discutido na seção anterior:

(2) "O pneu, ele tem uma borracha especial com alguma parte dentro da borracha que é aderente." (NURC-70/Salvador_354)

Dessa forma, temos que o SN “O pneu” é um tópico retomado no interior do comentário pelo pronome sujeito "ele". O tópico localiza-se em TopP, na camada CP (Rizzi, 1997) da estrutura sintática, para onde os sintagmas são movidos em função da checagem de traços discursivos.

Kato (1989) e Galves (1998) reafirmam a posição periférica do tópico na sentença. Essa posição está de acordo com a cartografia sintática proposta por Rizzi (1997, 1999), segundo a qual, na camada CP, o tópico ocupa a posição Spec, Top.

Para ocupar uma posição nessa estrutura, é necessário que o elemento atenda a algumas especificidades semântico-sintáticas - e, no caso dos elementos de $\mathrm{CP}$, discursivas. Para tanto, é necessário compreender a organização sintática dos constituintes proposta pelo autor.

Nessa organização, destacam-se as três camadas de análise: a lexical (vP), onde ocorre a inserção dos elementos lexicais, chamada primeiro merge $e^{1}$; a flexional (TP), para onde os elementos se movem a fim de checarem traços flexionais/morfológicos; e a camada discursiva $(\mathrm{CP})$, onde os elementos verificam seus traços discursivos. O tópico se encontra no Spec do núcleo Top dessa última camada, podendo ou não ser retomado por outro elemento no interior da oração (em IP ou vP). Ilustramos no diagrama sintático abaixo as posições projetadas, seguindo a proposta do Programa Minimalista: as posições são projetadas apenas se necessárias, ou seja, se houver requisição de checagem de traços

\footnotetext{
${ }^{1}$ Merge é a concatenação ou a entrada de elementos na derivação da sentença, portanto é a operação básica da derivação sintática. O merge externo ocorre na primeira fase da derivação, quando elementos do léxico são selecionados para constituir o objeto sintático. O merge interno corresponde aos movimentos que os constituintes realizam no interior da estrutura sintática.
} 
(CHOMSKY, 1999). A estrutura abaixo apresenta todos os núcleos e Specs projetados para fins didáticos:

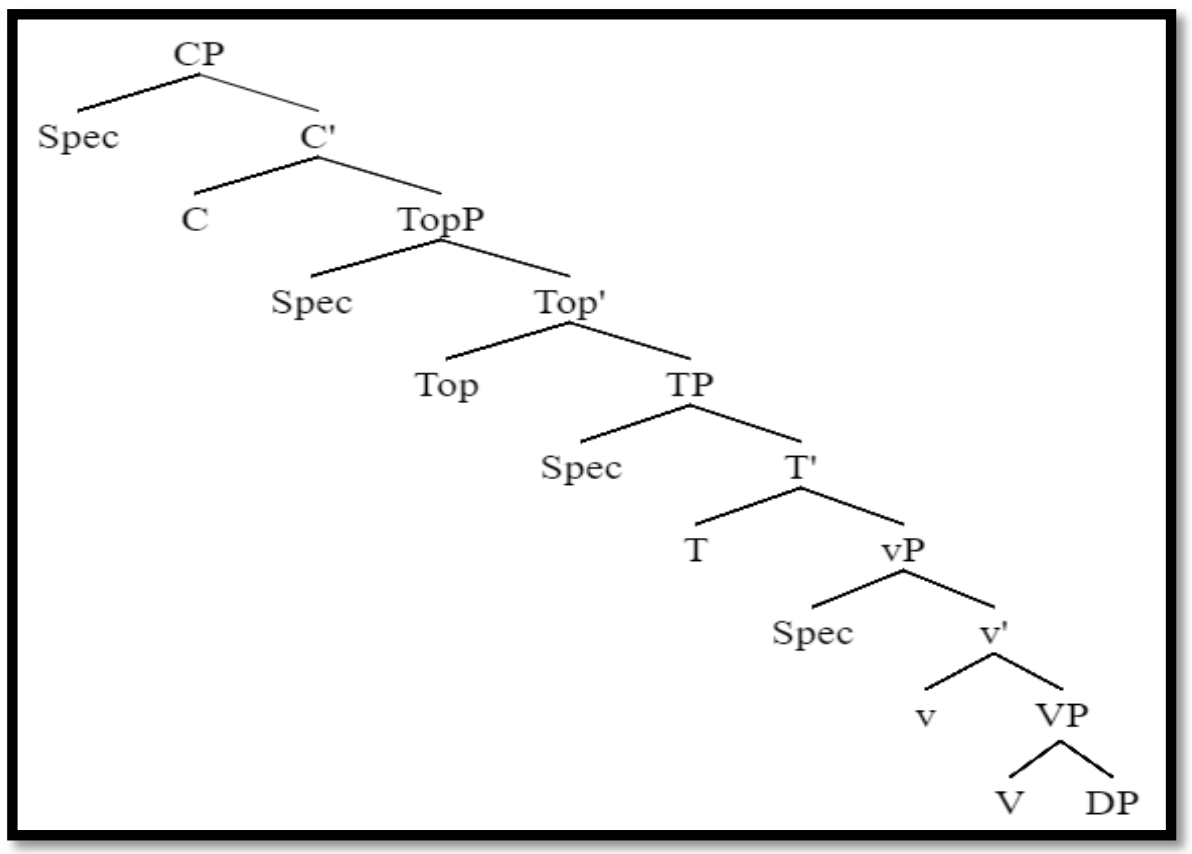

Figura 1 - representação arbórea das camadas da frase

Fonte: criada pelos autores através da ferramenta Syntax Tree Generator.

Dada a estrutura, é importante ressaltar que há, sintaticamente, dois tipos de tópico. Um se constitui de tópicos não-argumentais, que têm seu primeiro merge em $\mathrm{CP}$, chamado merge externo, conforme exemplo (3):

(3) "telefone, a gente tem que ter muito cuidado" (V14_PB)

Essa ocorrência foi extraída de um contexto em que a informante respondia à pergunta "É preciso colocar o telefone no currículo?". Percebemos, então, que há uma sentença completa que se refere ao tópico "telefone", mas que esse não tem referente no interior da sentença. Isso quer dizer que o SN não foi movido para Spec, Top, mas já sofreu nessa posição o seu primeiro e único merge. Isso acontece quando o elemento não tem traços para checar, nas camadas mais baixas da estrutura, o que o leva a ser inserido (sofrer merge) diretamente em TopP para checar o traço [Top].

Pontes (1987) já apontava para este fato, trazendo exemplos em que o tópico estabelece apenas uma relação semântico-discursiva com o verbo e com o restante da sentença. Portanto, não há obrigatoriedade de ligação sintática entre o tópico e qualquer outro elemento da oração que se constitui como comentário, como se pode observar em (3) e também em (4): 
(4) "As cadeiras optativas, cê precisa ter um bom conhecimento primeiro." (PONTES, 1987. Grifo nosso.)

Qualquer reorganização de (3) ou de (4) que venha a incluir o tópico como elemento pertencente ao interior das sentenças, sintaticamente ligado ao verbo, será forçosa e artificial. Além disso, é preciso considerar a espontaneidade da enunciação do falante, que produziu a frase exatamente como está transcrita, de forma natural. Pontes (1987) adiciona:

A frase [...] não deve ser entendida como se o SN "as cadeiras optativas" tivesse sido deslocado para a esquerda a partir de algo como "Você precisa ter um conhecimento bom primeiro das cadeiras optativas", mas sim como "As cadeiras optativas, cê precisa ter um conhecimento bom primeiro, antes de cursá-las". No contexto em que foi dita, ficou evidente esse sentido. Parece-me impossível formular uma transformação de topicalização para este tipo de construção. (p. 14)

Por outro lado, há um tipo de tópico que é estabelecido com base em merges internos, ou seja, em movimentos de um constituinte argumental de posições mais baixas para Spec, Top - passando pelas posições intermediárias que forem necessárias, conforme Rizzi (2004). Analisemos o exemplo em (5) a seguir:

(5) “O betacaroteno, ele vai ajudar na produção da melanina” (V19_PB)

A retomada pelo pronome "ele" no interior da sentença atesta que o tópico "O betacaroteno", na periferia, não foi inserido diretamente na posição Spec, Top, mas se moveu para esta posição, tendo sofrido merge externo em VP e interno para Spec, vP e, posteriormente, Spec, TP, até checar a Spec, TopP.

\subsection{O Tópico Pendente com Retomada (TPR)}

Construções desse tipo, segundo a proposta de Brito, Duarte e Matos (2003), são aquelas em que o tópico estabelece, além da relação semântica, uma relação sintática com um elemento interior à oração, havendo concordância em traços sintáticos entre o tópico e o seu correferente. A retomada do tópico no interior da oração pode ser feita por uma expressão lexical ou por uma categoria vazia (em posição de sujeito).

Os casos de retomada por clítico em que o tópico é marcado por uma das expressões citadas acima como indicadoras de tópico foram classificados como TPR, conforme proposta de Araújo (2006). Os exemplos em (6) e (7) representam, respectivamente, uma retomada lexical e uma por pronome nulo:

(6) “(...) a gente, provavelmente, a gente só encontraria casas, assim, bem modernas" (NURC-70/Salvador_173)

(7) “Nós, a gente aqui, pode, por exemplo, chover em novembro e de novembro para cá praticamente Ø não apanhámos água” (crpc_673) 
As retomadas de tópicos em posição de objeto direto são caracterizadas como TPR apenas se realizadas por pronomes plenos e SNs. Retomadas nulas em posição de objeto se enquadram como ETop ou em Topicalização de Objeto de Direto. $\mathrm{Na}$ verdade, conforme o demonstram Brito, Duarte e Matos (2003) e Araujo (2006, 2009), há vários tipos de construção de tópico. Por questão de espaço e do propósito relacionado ao artigo, estamos nos restringindo às construções de tópico com retomada na posição de sujeito.

\section{METODOLOGIA}

Os corpora da pesquisa foram constituídos a partir de três fontes: i) inquéritos disponibilizados virtualmente por projetos de pesquisa da Universidade de Lisboa; ii) transcrições dos inquéritos do Projeto Norma Urbana Culta, de 1970, referido neste trabalho como NURC-70 da cidade de Salvador; e iii) entrevistas concedidas a programas televisivos do Brasil e de Portugal na década de 2010. A partir dessas fontes, dividimos os inquéritos em quatro partes: PE da década de 1970, PB da década de 1970, PB da década de 2010 e PE da década de 2010. Todas as ocorrências foram extraídas de inquéritos do tipo Diálogo entre Informante e Documentador (DID).

A primeira parte dos corpora de análise, constituída por ocorrências do PE na década de 1970 e pautada em circunstâncias reais de fala espontânea dessa variedade, teve como base dois projetos realizados em Portugal, dedicados à produção oral da língua. $\mathrm{O}$ primeiro projeto dessa etapa é denominado Português Falado - Variedades Geográficas e Sociais, do Corpus de Referência do Português Contemporâneo (CRPC) ${ }^{2}$, que é desenvolvido no Centro de Linguística da Universidade de Lisboa (CLUL). A outra base de dados, da Universidade de Lisboa, é o Corpus Português Fundamental (PF), projeto iniciado por Lindley Cintra, em 1970. O PF - Amostra Publicada, descrito como sub-corpus e também integrante do CRPC, conta com 140 gravações transcritas, de aproximadamente 5 minutos cada.

A segunda parte do corpus diz respeito ao PB da década de 1970 e se baseou nos inquéritos transcritos pelo projeto NURC-70 da cidade de Salvador, dos quais foram analisados 8 inquéritos transcritos com durações entre 40 e 50 minutos cada, resultando em cerca de 6 horas de áudio transcrito.

Para as ocorrências da década de 2010 do PB e do PE, correspondentes, respectivamente, à terceira e à quarta partes da divisão dos corpora da nossa pesquisa, trabalhamos com dados bastante recentes, ainda não encontrados em corpora prontos. Portanto, constituímos os corpora de ambas as variedades da mesma forma: a partir da coleta de ocorrências em vídeos de entrevistas jornalísticas ocorridas entre 2010 e 2015, disponibilizados nos sites das emissoras de televisão brasileiras e portuguesas e na rede social YouTube. Tanto para o PB quanto para o PE, foram coletados dados provenientes de 3 horas de escuta. Do PB, foram assistidos 27 vídeos entre 5 e 15 minutos. Do PE, foram assistidos 15 vídeos também com a faixa de duração entre 5 e 15 minutos.

${ }^{2}$ Disponível em: <http://www.clul.ul.pt/pt/recursos/183-crpc\#cqp>. Acesso em: 24 dez 2016 
Nos corpora da década de 1970, tanto para o PB quanto para o PE, foram extraídas ocorrências de anos variados entre 1970 e 1979. Nos corpora da década de 2010, foram extraídas ocorrências de entrevistas que aconteceram entre 2010 e 2013. Dessa forma, sempre que nos referirmos a 1970 ou 2010, estaremos remetendo à década, não ao ano específico.

\section{RESULTADOS E ANÁLISE}

Este item abriga a exposição dos resultados obtidos após classificação dos dados levantados na pesquisa. Organizamos as informações de acordo com as décadas pesquisadas e com as variedades da língua na Tabela 1.

\begin{tabular}{|l|l|l|l|l|}
\cline { 2 - 5 } \multicolumn{1}{c|}{} & \multicolumn{2}{c|}{ PB } & \multicolumn{2}{c|}{ PE } \\
\hline $\mathbf{1 9 7 0}$ & $45 / 86$ & $52 \%$ & $38 / 65$ & $58 \%$ \\
\hline $\mathbf{2 0 1 0}$ & $66 / 79$ & $83 \%$ & $13 / 18$ & $72 \%$ \\
\hline
\end{tabular}

Tabela 1: Tópico Pendente com Retomada na posição de sujeito

Os dados constantes na Tabela revelam que: $1^{\circ}$ dentre a quantidade de construções de tópico encontradas nas duas variedades, o PB apresenta número superior ao do PE nas duas décadas; $2^{\circ}$ comparando-se as décadas e as variedades, há manutenção das construções de tópico no PB, com nítida redução no PE; $3^{\circ}$ as construções de tópico com retomada na posição de sujeito apresenta maior quantidade em ambas as variedades, em detrimento dos outros tipos.

\subsection{RESULTADOS DE 1970}

- Dados do PB-1970

É possível perceber que há uma clara superioridade de ocorrências de TPR em relação aos outros tipos no PB da década de 1970. As construções desse tipo representam mais de $50 \%$ de todo o material coletado nesaa década e nessa variedade. Entre essas ocorrências, destaca-se a retomada de tópicos em posição de sujeito, como exemplificado em (8) e (9):

(8) “A minha irmã mesmo, ela se dá bem com as estudantes” (NURC-

70/Salvador_231)

(9) “O avião grande, ele é bem mais seguro” (NURC-70/Salvador_227)

\section{- Dados do PE-1970}

Assim como no PB, também se destacaram no PE as construções de TPR, com mais de 50\% do total. Na década de 1970, a retomada aconteceu 30 vezes na posição de sujeito, sendo 27 delas realizadas por pronomes, como se exemplifica em (10), e 3 por SNs, em (11): 
(10) $\underline{\text { Eu }}$, eu acho que isso é absolutamente lamentável (crpc_187)

(11) O juiz, normalmente o juiz que começa a sua carreira logo pela magistratura, e normalmente assim sucede (crpc_108)

Diferentemente do $\mathrm{PB}$, porém, as retomadas de sujeitos por pronomes plenos não foram as mais recorrentes no PE. Das 27 ocorrências de tópicos retomados por pronomes na posição de sujeito, 11 apresentaram retomadas por pronomes nulos, conforme (12) e (13):

(12) O pai nem se sabe onde $\boldsymbol{\emptyset}$ pára nem, nem onde $\boldsymbol{\varnothing}$ deixa de parar (crpc_53)

(13) Tá bem, eu isso $\varnothing$ concordo... (crpc_1020)

Entre as 16 retomadas por pronome pleno, observamos que 11 acontecem logo em seguida a um tópico que também é pronome, tanto na oração principal quanto na subordinada, como ilustrado em (14) e (15), respectivamente:

(14) Eu, eu já reparei que é um dos factores que leva (crpc_184)

(15) Estava sempre longe que ele, ele não se decidia a apanhar de vez, ou que não era capaz de apanhar... (crpc_194)

Outras 4 ocorrências apresentam uma configuração semelhante, mas contam com a presença de material interveniente entre o tópico e a retomada:

(16) $\underline{\mathrm{Eu}}$, então, eu gostava imenso até de ter um colégio, ou uma casa qualquer, para me dedicar à investigação desses problemas. (crpc_832)

(17) Não, ele, fisicamente, coitadito, ele bem diz que tem uma boa perna, mas... Nós... Ainda é pior! (crpc_122)

A última ocorrência de retomada pronominal foi um caso atípico no PE, mas muito recorrente no $\mathrm{PB}$ :

(18) Os miúdos, por amor de deus, eles saem duma sala, têm dez minutos (...) (crpc_221)

\subsection{RESULTADOS DE 2010}

\section{- Dados do PB-2010}

Assim como nos dados de 1970, o PB apresentou, em 2015, larga superioridade das construções de TPR em relação aos outros tipos. Entre as possibilidades de retomada do tópico, destacou-se, novamente, a pronominal em posição de sujeito, conforme exemplos (19) e (20): 
(19) "Essa cartilha, ela fala sobre o ciclo de violência doméstica, de uma forma bem simples" (V19_PB)

(20) "O organismo nosso, ele precisa, na verdade, de uma hidratação maior" (V17_PB)

Das 66 ocorrências de TPR, 63 seguiram a estrutura sintática dos exemplos acima, inclusive utilizando o pronome pessoal, flexionando em número e gênero de acordo com a morfologia do tópico. $\mathrm{Na}$ década de 2010, as retomadas pronominais na função de sujeito mais que dobraram, aparecendo 63 vezes com menos tempo de escuta. A proporção de retomadas de tópico em posição de sujeito por pronomes tem, portanto, manifestado um aumento expressivo, enquanto outras possibilidades de retomada com a mesma função sintática estão provavelmente em decadência.

As outras 2 retomadas foram realizadas por pronome demonstrativo, em (21), e por pronome nulo, em (22):

(21) “A jornada, essa é obrigatória." (V4_PB)

(22) "A adolescência, a gente costuma dizer que $\boldsymbol{\emptyset}$ é um transtorno que só o tempo vai curar" (V9_PB)

\section{- Dados do PE-2010}

As construções de TPR, assim como nos outros corpora, tanto do PE quanto de PB, foram numericamente superiores às demais. Entretanto, a totalidade de ocorrências do PE em 2010 foi muito inferior à do PB na mesma década ou em 1970. Além disso, é notável a redução de produtividade do PE entre 1970 e 2010.

No corpus de 2010 do PE, 9 retomadas apareceram em posição de sujeito. Essas retomadas aconteceram de várias formas: por pronomes nulos (23), por pronomes plenos (24), SNs cópias (25) e demonstrativos (26):

(23) "E o David, naquele dia, acho que $\emptyset$ leu as coisas mais rápido do que o habitual" (V7_PE)

(24) "O boldo, além de melhorar na questão do enfartamento, ele vai depois, também, ter uma ação laxante suave" (V15_PE)

(25) "a mais-valia para alguém que vai para uma universidade, em termos de salário no mercado de trabalho, a mais-valia é maior em Portugal do que no resto dos países da OCDE" (V3_PE)

(26) "Quem age pode vir a cometer um erro, mas quem não age, esse já cometeu um erro." (V8_PE)"

De modo geral, observamos, na primeira década, menos discrepâncias entre os tipos de tópico em cada variedade e também entre os totais de produtividade de cada uma. $\mathrm{Na}$ segunda década, foi possível observar aumento no total de ocorrências do PB e decréscimo no PB. É preciso observar que o aumento em PB só foi possível graças às construções de TPR que se mostraram muito mais frequentes em 2010. Embora não se tenha verificado o mesmo movimento em PE, essa variedade também apresentou as TPR 
em número muito maior do que os outros tipos. Revela-se, dessa forma, a nossa escolha por dedicar o presente artigo a esse tipo de construção.

\section{AS RELAÇÕES ENTRE SUJEITO E TÓPICO NO PB A PARTIR DAS TPR}

Entre as possibilidades de retomada do tópico em posição de sujeito estudadas neste trabalho, encontramos a retomada por pronomes plenos, por pronomes nulos e por sintagmas nominais, com flagrante superioridade dos primeiros, tanto em 1970 quanto em 2010.

Tal tipo de retomada, conforme demonstram os dados, pode estar relacionada à tendência de preenchimento do sujeito no PB, defendida pelos estudiosos brasileiros, como Tarallo (1993), Duarte (1993, 1995, 2008), Cyrino (1994), Galves (1996), Kato, Duarte, Cyrino e Berlinck (2006), Duarte e Varejão (2013), entre outros.

Tarallo (1993) defende que, entre o final do século XIX e meados do século XX, PB e PE passam por um processo de afastamento entre suas gramáticas, em especial quanto às configurações sintáticas de cada variedade. Para discutir essa ideia, o autor leva em consideração cinco fenômenos: a perda seletiva do sujeito nulo; o aparecimento do objeto nulo referencial; a perda da inversão verbo-sujeito em interrogativas-Q; as estratégias de relativização; e a perda de inversão não-acusativa. A partir da observação desses fenômenos, o autor verifica que o PB, a partir do século XIX, começava a apresentar características diferentes do PE, como a tendência à perda da inversão livre entre sujeito, verbo e complemento e a perda do sujeito nulo, que é o ponto mais relevante para nossa pesquisa. $\mathrm{O}$ autor defende que essa mudança decorre de um movimento de perda do parâmetro pro-drop em $\mathrm{PB}$, o que não se verifica no $\mathrm{PE}$. O parâmetro pro-drop é o que permite a realização de sujeitos nulos em línguas cujos sujeitos possam ser expressos através da morfologia verbal.

Alguns anos mais tarde, alguns desses fenômenos sintáticos (exceto as relativizações) são estudados no PB por Kato, Duarte, Cyrino e Berlinck (2006), que atestam as hipóteses do autor sobre as diferenças entre PB e PE.

As autoras confirmaram que, a partir da segunda metade do século $\mathrm{XX}$, as construções com sujeito nulo no PB passam a ser menos frequentes do que as de sujeito preenchido. Isso representa um distanciamento sintático do $\mathrm{PB}$ em relação ao $\mathrm{PE}$, que oferece menos restrições contextuais para a produção de sujeitos nulos, conforme Duarte (1993, 1995, 2008), Galves (1996, 1998), Figueiredo Silva (1996) e Kato (1999), por exemplo. Essa diferença, segundo trabalhos de Duarte (1993) Lopes e Cunha (1994), Paredes Silve (2000), Lopes (2003), entre outros, é decorrente da instabilidade causada no paradigma pronominal do PB através da gramaticalização e consequente inserção de dois novos pronomes você $(s)$ - para a $2^{\mathrm{a}}$ pessoa do discurso, singular ou plural - e a gente, para a $1^{\text {a }}$ pessoa do plural. A estabilização do uso dessas formas como pronomes pessoais levou ao desequilíbrio do sistema composto por seis formas (eu, tu, ele, nós, vós, eles), com respectiva redução nas flexões verbais, que passaram de seis a três, conforme indicam os estudos na área. 
É possível que o aumento da produtividade de tópicos com retomada pronominal em posição de sujeito seja indício de uma nova configuração no PB. Acreditamos que o PB está realizando concordância de pessoa entre sujeito e verbo através do pronome pleno, e não mais através de marcas morfológicas flexionais, conforme defende Galves (1996, p. 395):

Em Galves (1991), propus considerar o elemento de concordância da flexão do PB como "fraco", definindo essa noção da seguinte maneira: é fraca a concordância que não tem pessoa, ou contém pessoa como um traço puramente sintático. É o que acontece no PB, onde não se encontra na flexão verbal a oposição $1^{\mathrm{a}}, 2^{\mathrm{a}}$ e $3^{\mathrm{a}}$ pessoas, mas somente uma oposição binária, pessoa $\left(1^{\mathrm{a}}\right) /$ não pessoa $\left(3^{\mathrm{a}}\right)$, articulada a uma oposição singular/plural. Isso corresponde a uma concordância fraca morfologicamente (ausência de $2^{\mathrm{a}}$ pessoa), e semanticamente (possibilidade de interpretar a terceira pessoa do singular como indeterminada).

Segundo as ideias da autora, corroboradas por Costa (2010), os verbos em PB estão perdendo a capacidade de checar o aspecto semântico do traço de pessoa através da desinência (que, portanto, passa a expressar apenas número). Se não há representação morfológica do traço de pessoa no verbo, esse traço assume um caráter exclusivamente sintático, pelo que precisa ser realizado fora do verbo através do pronome, como se observa em (27) e (28):

(27) "O tomate, por exemplo, ele pode ser armazenado fora da geladeira" (V16_PB)

(28) “essas escolhas, elas são difíceis, elas são complexas" (V2_PB)

Um tipo de arranjo interessante relativamente à proposta de Galves (1996) é o preenchimento de sujeito mesmo quando há, no verbo, marcação morfológica de flexão em pessoa, ou seja, situações de sujeito preenchido com verbo flexionado em primeira pessoa - e, portanto, marcado positivamente para a flexão em pessoa. No corpus do PB, foram encontradas 8 ocorrências desse tipo, exemplificadas abaixo:

(29) “Eu... isso aí eu não sei” (NURC-70/Salvador_100)

(30) "Eu, realmente, eu me pego mais... pego mais aqui é inverno e verão" (NURC70/Salvador_135)

Essas construções, da década de 1970, podem representar indícios de que os falantes do PB já não tinham mais a percepção plena de que as desinências verbais carregam traço de pessoa, nem mesmo considerando-se um sistema binário ${ }^{3}$, como proposto por Galves (1996). Dessa forma, podemos deduzir que as retomadas

\footnotetext{
3 O sistema binário é a oposição entre marcação e não marcação de pessoa, conforme explica Galves (1996, p. 395). Assim, não haveria várias possibilidades de marcação desse traço no $\mathrm{PB}$, como no paradigma europeu (de 6 pessoas), mas apenas duas: traço de pessoa marcado (através da flexão de $1^{a}$ pessoa singular) e traço de pessoa não marcado (em que as outras pessoas do paradigma não recebem marcas flexionais que sinalizem a presença do traço).
} 
pronominais de tópico em posição de sujeito têm tendência a crescimento em PB, uma vez que o enfraquecimento do traço de pessoa parece atingir todo o paradigma flexional, e não apenas a $3^{a}$ pessoa.

$\mathrm{Na}$ década de 2010, não foram encontradas retomadas envolvendo a $1^{\mathrm{a}}$ pessoa, mas apenas com a $3^{a}$ pessoa. Acreditamos que essa ausência tenha relação com os assuntos abordados pelos informantes enquanto eram entrevistados, uma vez que, para garantir o controle da variável "escolaridade", selecionamos entrevistas de profissionais em áreas que exigem curso superior. Nessas entrevistas, os informantes estavam sendo convidados para falar sobre assuntos de sua especialidade, pelo que raramente faziam uso da primeira pessoa. Além disso, os tempos de cada entrevista no NURC e no corpus PB 2010 foram muito diferentes, o que pode ter reduzido as possibilidades de encontrarmos ocorrências deste tipo em 2010. No primeiro, cada inquérito tinha, no mínimo, 40 minutos de áudio transcrito, enquanto, no segundo, as entrevistas chegaram ao tempo máximo de 15 minutos. Por outro lado, no corpus mais atual, foi possível investigar mais falantes, que, embora não tenham realizado o traço de $1^{a}$ pessoa fora do verbo, realizaram o traço de $3^{a}$ pessoa com mais frequência do que em 1970, reforçando a hipótese da perda do traço de pessoa no verbo. Exemplos da produtividade de 2010 nesse sentido são expostos em (31) e (32):

(31) “A questão da taxação do capital próprio, ela é um incentivo para a empresa reinvestir os seus lucros"

(32) "As normas coletivas, elas podem prever algo que seja mais favorável ao trabalhador"

Cyrino, Duarte e Kato (2000) propõem uma escala de referencialidade relativa ao preenchimento pronominal do sujeito e sugerem que os SNs mais referenciais têm mais chances de serem retomados por pronomes realizados. No topo da hierarquia de referencialidade, estariam argumentos com traços [+espec, +humano], com SNs portadores de traços [-humano] mais abaixo, enquanto os não-argumentos estariam na última parte da escala, conforme ilustração retirada do texto:

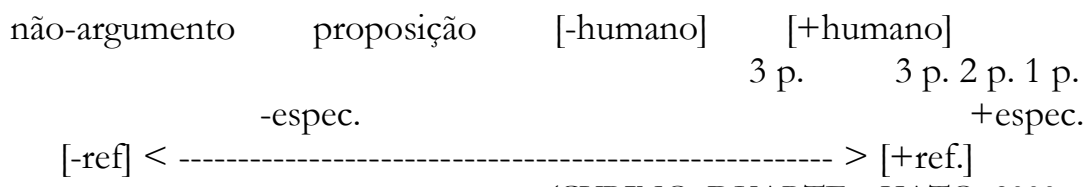

(CYRINO, DUARTE e KATO, 2000, p. 422)

Considerando o preenchimento do sujeito no PB, Kato e Duarte (2014) sugerem que esse seja uma variedade de sujeito nulo parcial por admitir oscilação entre preenchimento e não preenchimento do sujeito. Nesse sentido, as autoras buscam propriedades sintáticas, semânticas e morfológicas que balizem tal variação. Entre as condições semânticas, destacam a referencialidade do elemento representado pelo pronome, conforme escala supracitada. As autoras dizem ainda que "a restrição ao pronome expresso, postulada em Chomsky através do princípio 'Evite pronome' para línguas de sujeito nulo (...) teria uma contraparte 'Evite pronomes não-referenciais' para 
línguas de sujeito nulo parciais como o PB" (KATO e DUARTE, 2014, p. 17). Assim, tópicos com traço com maior grau de referencialidade, naturalmente, favoreceriam mais a ocorrência de retomadas pronominais no interior da oração do que tópicos menos referenciais. Considerando que os tópicos sempre são altamente referenciais, os nossos dados confirmam a hipótese das autoras, dado o crescimento de construções de TPR entre as décadas de 1970 e 2010.

Em relação à animacidade do tópico nas construções de TPR, as retomadas pronominais em posição de sujeito dos SNs com o traço [-humano] foram superiores às de SNs com traço [+humano] em ambas as décadas. Mais do que isso, verificamos que, na década de 2010, houve um aumento expressivo de retomadas de SNs [-humano], tanto em relação à década de 1970 quanto em relação às retomadas de SNs [+humano], conforme Tabela abaixo:

\begin{tabular}{|c|c|c|}
\hline PB & $\begin{array}{c}\text { Retomadas de SN com traço } \\
\text { [+humano] }\end{array}$ & $\begin{array}{c}\text { Retomadas de SN com traço } \\
{[\text {-humano] }}\end{array}$ \\
\hline 1970 & 15 & 16 \\
\hline 2010 & 20 & 42 \\
\hline
\end{tabular}

Tabela 2 - Retomadas em posição de sujeito de acordo com a animacidade do tópico no PB.

Os dados da Tabela 2 revelam que, no $\mathrm{PB}$, há uma tendência crescente à retomada de tópicos com o traço [-humano]. A alta produtividade de tópicos com esse traço, segundo Paula e Orsini (2016), é um indicativo de que o PB vem se tornando uma língua de sujeito preenchido. As autoras argumentam:

[...] constata-se que o PB licencia qualquer tipo de SN, independente de seus traços semânticos e da sua especificidade. Tal comportamento é uma evidência de que a posição de tópico está disponível e pode ser preenchida, uma consequência da mudança na marcação do Parâmetro do Sujeito Nulo já ter atingido todos os contextos previstos pela hierarquia de referencialidade, de Cyrino, Duarte e Kato (2000), evidenciando o princípio do encaixamento, segundo Weinreich, Labov e Herzog (1968[2006]). (p. 11)

Nesse sentido, reforça-se a hipótese de que as retomadas de tópicos em posição de sujeito atendem à necessidade de realização do traço de pessoa fora do verbo em decorrência de uma mudança nas configurações de checagem de traços dos verbos em PB, conforme Galves (1996), já mencionada neste artigo.

As retomadas de sujeito por pronome nulo, por sua vez, foram encontradas apenas em duas ocorrências no corpus do PB, uma em 1970, exemplificada em (33), e outra em 2010, exemplificada em (34):

(33) "Samba, creio que Ø possa ser uma música regional" (NURC-70/Salvador_125)

(34) "A adolescência, a gente costuma dizer que $\boldsymbol{\emptyset}$ é um transtorno que só o tempo vai curar" (V9_PB) 
É interessante observar, entre as duas ocorrências encontradas, uma peculiaridade relativa à retomada por pronome nulo. Numa projeção de preenchimento pronominal de sujeito da oração subordinada, (33) parece soar agramatical, enquanto (34) parece uma frase boa, conforme se exemplifica abaixo:

(33)' Samba, creio que ele possa ser uma música regional.\#

(34)' A adolescência, a gente costuma dizer que ela é um transtorno que só o tempo vai curar.

Acreditamos que a determinação do tópico, nesses casos, pode ser o que permite a aceitação da retomada pronominal no segundo caso, mas não no primeiro. Assim, parece confirmar-se a ideia de que os pronomes pessoais estão mais ligados à retomada de referentes determinados, enquanto referentes indeterminados relacionam-se mais frequentemente com retomadas nulas ou retomadas por SNs.

Kato e Duarte (2014, p.17) julgam que a mudança sintática no PB, distanciando-se do PE, "não é apenas efeito de uma mudança em curso, mas que ela pode ser explicada como propriedades de uma gramática estável caracterizável em termos de restrições semânticas de referencialidade e de propriedades morfossintáticas”. É também isso que os nossos dados insinuam, uma vez que a retomada de tópico por sujeito nulo se mostra pouco frequente tanto em 1970 quanto em 2010 e só apareceu retomando referentes com traço [-humano], confirmando as projeções das autoras.

Embora os números indiquem que parece não haver restrição ou tendência de preenchimento de sujeito motivada pelo traço [+humano], é importante lembrar que as construções de tópico sempre são condicionadas pelo contexto de produção. Assim, é possível que a maioria das ocorrências em questão tenha sido coletada de situações de fala em que o informante não tivesse necessidade de mencionar tópicos com o traço [+humano]. Supomos que, se o assunto estivesse em torno de referentes [+humanos], poderíamos ter encontrado uma porcentagem maior de retomadas pronominais de SNs com este traço. O que queremos enfatizar quanto aos dados é que o traço de animacidade não exerce influência relevante sobre a realização da retomada pronominal do tópico, diferentemente do que trazem estudos anteriores, como os de Braga (1987), Duarte (2003) e Cyrino, Duarte e Kato (2006), Santos (2009) e Duarte e Paiva (2011), entre outros.

\section{AS RELAÇÕES ENTRE SUJEITO E TÓPICO NO PE A PARTIR DAS TPR}

Conforme visto na seção 4, as ocorrências de TPR foram as mais frequentes também no PE. As retomadas em posição de sujeito foram recorrentes. Entre as ocorrências deste tipo, duas chamaram a nossa atenção por terem uma configuração muito comum para o PB, mas pouco encontradas no PE:

(35) "Os miúdos, por amor de deus, eles saem duma sala, têm dez minutos (...)" (crpc_221) 
(36) "O boldo, além de melhorar na questão do enfartamento, ele vai depois, também, ter uma ação laxante suave" (V15_PE)

É possível que as construções desse tipo sejam comuns nas línguas naturais. Entretanto, em decorrência de especificidades de cada gramática, as TPR com retomada pronominal em posição de sujeito são mais recorrentes em algumas gramáticas do que em outras, como ocorre com frequência em PB e, mais raramente, em PE.

Por utilizarem uma variedade de flexão rica, os falantes do PE podem abrir mão do preenchimento da posição de sujeito mais facilmente do que os falantes do PB, cuja língua de que dispõem apresenta flexão pobre, conforme Galves (1996). Isso contribui para que as construções de TPR sejam abundantes na variedade brasileira, mas não na portuguesa.

O que determina as diferenças entre as ocorrências, então, não é a produtividade, mas são as formas como se expressam em cada variedade, uma vez que as retomadas pronominas plenas se mostram mais frequentes no $\mathrm{PB}$, enquanto outras formas de retomada são preferidas no $\mathrm{PE}$, como os pronomes nulos e os $\mathrm{SNs}$ plenos. Isso leva alguns autores a sugerir que haja substanciais diferenças entre as estruturas subjacentes às construções desse tipo em cada gramática. Ou seja, embora a estrutura da superfície seja aparentemente igual entre os exemplos apresentados, há diferenças profundas na sintaxe de cada variedade - PB e PE - conforme o indicam alguns autores.

Barbosa (1995) postula que, nas línguas de sujeito nulo, como é o caso do PE, o lugar do sujeito na sentença é sempre pós-verbal, podendo ocupar uma posição pré-verbal somente a partir de deslocamento (que ocorre através de adjunção) ou a partir de um movimento decorrente de focalização. A posição pré-verbal a que se destina o SN sujeito, entretanto, não é SPec, TP, como ocorre no PB, ou como propõe Costa (2000) para o PE. A autora sugere a adjunção de uma projeção funcional (FP), que abrigará sintagmas com importe discursivo, como tópicos e focos. Dessa forma, construções com sujeito pré-verbal, em PE, sempre seriam condicionadas discursivamente, seja como tópicos, seja como focos (informacionais ou contrastivos). A organização proposta pode ser ilustrada em (37):

(37) Eu, eu acho que isso é absolutamente lamentável (crpc_187)

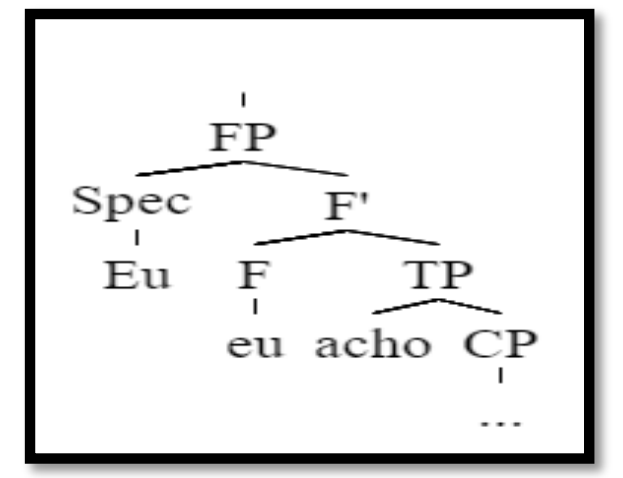

Figura 2 - representação da proposta de Barbosa (1995) 
Fonte: criada pelos autores através da ferramenta Syntax Tree Generator

Nos casos que são exemplificados em (37), segundo Barbosa (2006), há um "deslocamento múltiplo" do sujeito pós-verbal para as duas posições em FP. A autora considera que "nada impede a deslocação múltipla (...). Prevê-se muito simplesmente que seja redundante. Com efeito, frases desse tipo são raras e, sempre que ocorrem, exigem uma pausa bastante acentuada entre o DP e o pronome." (p. 32). Entretanto, essa análise se mostra problemática, nos exemplos (38)-(39), em que há material interveniente entre o tópico e a sua retomada (entendida aqui como foco):

(38) $\underline{\text { Eu}, ~ e n t a ̃ o, ~ e u ~ g o s t a v a ~ i m e n s o ~ a t e ́ ~ d e ~ t e r ~ u m ~ c o l e ́ g i o, ~ o u ~ u m a ~ c a s a ~ q u a l q u e r, ~ p a r a ~ m e ~}$ dedicar à investigação desses problemas. (crpc_832)

(39) $\mathrm{Eu}$, portanto, eu dizia que neste mundo frio, engessado, cheio de máquinas, que nós não podíamos negar a in(...) A, o, a parte espiritual e, e, e... Do homem (crpc_93)

O problema se dá pelo fato de a estrutura proposta pela autora não dispor de posições para receber o material interveniente, uma vez que o tópico e o foco "dividiriam" a mesma projeção, ocupando os dois as duas únicas posições possíveis: Spec e Núcleo de $\mathrm{FP}$, respectivamente.

Barbosa $(1995,2006)$ faz ponderações inquestionáveis sobre o fato de o PE não projetar a posição Spec, TP, visto que o núcleo T é capaz de checar o traço de pessoa (D) através da flexão verbal. Isso faz com que o sujeito do PE, em construções de TPR, ocupe algum outro lugar na estrutura e, para tanto, a autora propõe o deslocamento para o núcleo da camada FP, como explicamos acima. O problema dessa proposta é que a projeção FP, como colocada pela autora, não consegue atender as construções de TPR com material interveniente entre tópico e sujeito.

A proposta de Rizzi (1997), por sua vez, admite que a estrutura sintática das línguas naturais seja dividida em 3 camadas (Lexical, Funcional e Complementizadora). A partir dessa estrutura básica, projeções lexicais e funcionais organizam-se internamente, alocando todos os sintagmas da frase de acordo com os traços presentes na derivação.

Dentro da camada CP, segundo Rizzi (1997, 2004), há duas projeções possíveis que são essenciais para o nosso trabalho: TopP e FocP, nesta ordem hierárquica. O autor admite ainda a existência de uma segunda projeção TopP abaixo de FocP. Todas essas projeções só ocorrem quando necessário, ou seja, quando há sintagmas que precisam efetuar checagem desses traços discursivos. Abaixo, demonstramos, de forma simplificada, a abertura dessas posições dentro do sistema CP, conforme modelo proposto pelo autor: 


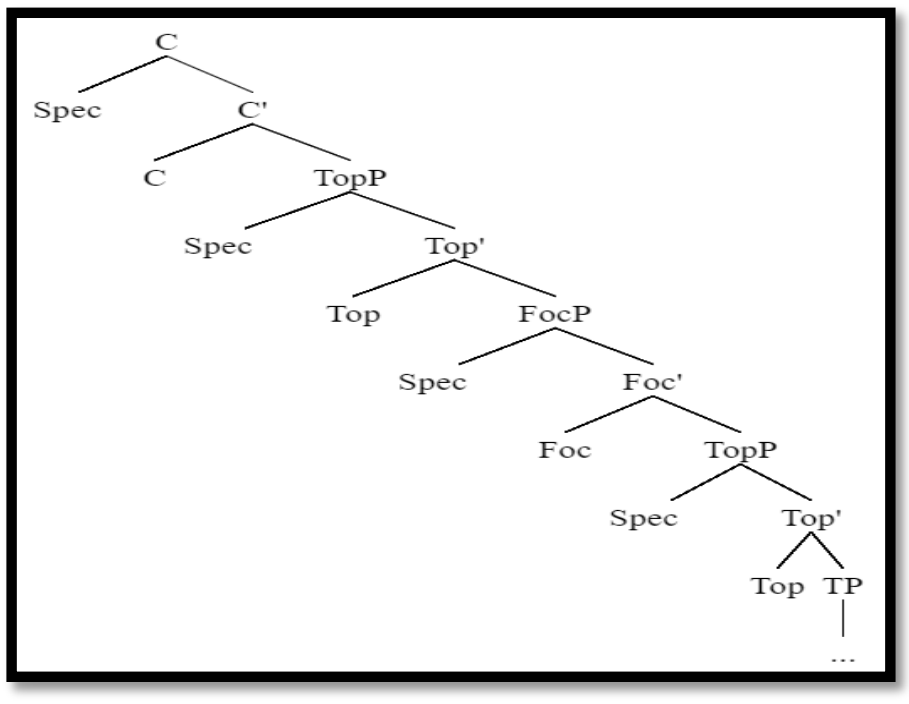

Figura 3 - Representação da proposta de Rizzi (1997, 2004)

Fonte: criada pelos autores através da ferramenta Syntax Tree Generator

Como visto na Figura 3, Rizzi (1997) prevê, para o italiano, Top $\rightarrow$ Foc $\rightarrow$ Top ou seja, para ele, existe a possibilidade de duas posições de tópico no sistema C. Araújo (2006), em contrapartida, discute a impossibilidade de isso acontecer no português, devido a fatores prosódicos que não permitem pausa entre o foco e a oração, impedindo a ocorrência de um tópico após um foco ${ }^{4}$, já que o tópico é comumente marcado por uma pausa na fala. Assim, considerando as ponderações da autora, admitimos, para o português nas duas variedades, apenas a posição TopP que se localiza acima da posição FocP.

A proposta minimalista da Teoria Gerativa tem defendido que o PE é uma língua de "sujeito nulo consistente", nos termos de Roberts \& Holmberg (2010). Línguas desse tipo têm o traço de pessoa (D-feature) no núcleo T, o que permite a checagem desse traço através da flexão verbal, não sendo sintaticamente necessária, portanto, a realização do sujeito. Assim, Spec, TP, no PE, não seria projetado, visto que, segundo o modelo minimalista, só são projetadas posições estritamente necessárias para a derivação da sentença.

Partindo das ideias de Roberts \& Holmberg (2010) e sabendo da estabilidade do sistema flexional verbal do PE, não parece haver motivos que levem à realização do sujeito (seja por pronome ou por $\mathrm{SN}$ ) para checagem de traços de pessoa em Spec, TP. Da mesma forma, mostramos que a proposta de Barbosa (2006), embora viável para analisar algumas ocorrências do PE, apresenta problemas com relação às posições do tópico e do foco. Percebemos isso a partir da análise de sentenças com material interveniente entre tópico e foco. Sendo assim, a estrutura proposta por Araújo (2006), a partir de Rizzi (1997), com duas projeções independentes, uma para tópico e outra para foco, parece mais adequada

${ }^{4}$ Para mais detalhes sobre essa questão, recomendamos a leitura de Araújo (2006). 
para dar conta de construções como as que aparecem nos exemplos em (38) e (39), uma vez que, entre o tópico e o foco, é possível a admissão de eventuais materiais intervenientes. Assim, só é possível que as ocorrências de retomada em posição de sujeito que encontramos no PE ocupem o núcleo de FocP, como ilustrado abaixo com a sentença do exemplo em (38):

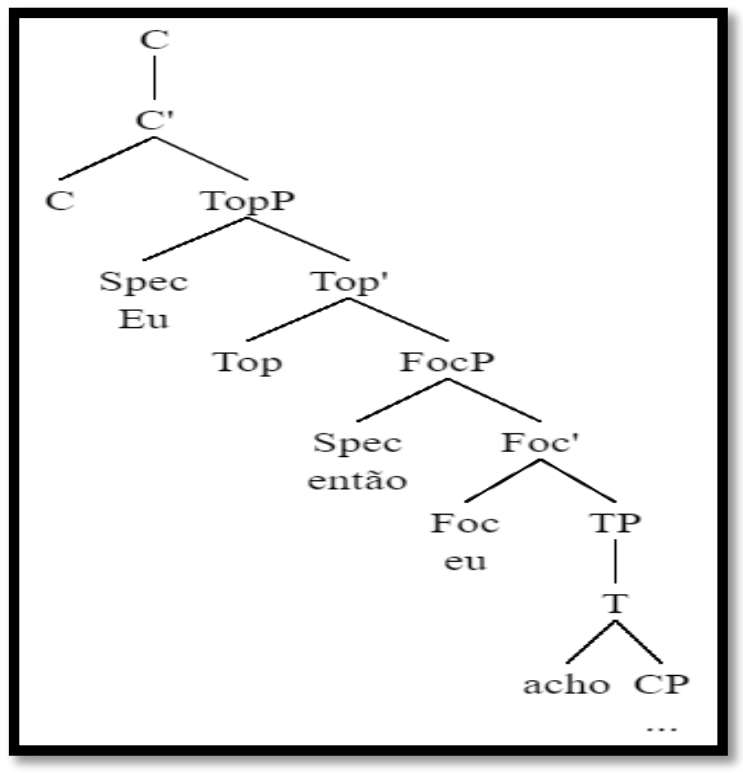

Figura 4 - representação do exemplo em (38)

Fonte: criada pelos autores através da ferramenta Syntax Tree Generator

A clivagem do pronome em (40) reforça a hipótese de que a retomada de tópico com função de sujeito no PE pode ocupar a posição de foco:

(40) "As minhas avós, sempre foram elas que, no fundo, seguraram as rédeas da gestão das casas" (V11_PE)

A partir dessa ocorrência, não é possível afirmar categoricamente que os sujeitos das outras sentenças estão em posição de foco, uma vez que não há marcas explícitas, como a clivagem em (40). Entretanto, percebemos que, nesse e nos exemplos em (38) e (39), todos os elementos que estamos querendo considerar como ocupantes da posição de foco atendem às condições sintáticas e semânticas para tal.

Portanto, quanto à estrutura sintática das TPR em PE, julgamos a proposta de Araújo (2006), baseada em Rizzi (1997), mais adequada do que a de Barbosa (1995, 2006). Embora a mesma proposta possa ser utilizada nas análises do PB e do PE, é importante ressaltar as diferenças estruturais entre as construções desse tipo em cada variedade, conforme detalhamos na seção anterior e nesta.

Em relação ao traço semântico, comparando-se $\mathrm{PB}$ e $\mathrm{PE}$, verificamos que as retomadas em posição de sujeito no $\mathrm{PE}$, diferentemente do $\mathrm{PB}$, ocorreram mais 
frequentemente com tópicos que possuem o traço [+humano] nas retomadas por pronomes nas duas décadas:

\begin{tabular}{|c|r|r|r|r|r|r|}
\hline \multirow{2}{*}{ PE } & \multicolumn{2}{|c|}{ Retomadas por SNs } & \multicolumn{2}{c|}{$\begin{array}{c}\text { Retomadas por } \\
\text { Pronome pleno }\end{array}$} & \multicolumn{2}{c|}{$\begin{array}{c}\text { Retomadas por Pronome } \\
\text { nulo }\end{array}$} \\
\cline { 2 - 7 } & {$[$ +hum] } & {$[$-hum] } & {$[$ [+hum] } & {$[$-hum] } & [+hum] & [-hum] \\
\hline 1970 & 3 & 4 & 18 & & 11 & 1 \\
\hline 2010 & 0 & 3 & 2 & & 6 & 1 \\
\hline
\end{tabular}

Tabela 3 - Retomadas em posição de sujeito de acordo com o tipo de retomada e com a animacidade do tópico no PE.

Para tópicos com o traço [-humano], a preferência foi por retomadas realizadas através de SNs. Essas tendências, observadas no corpus da década de 1970, foram confirmadas em 2010, conforme representado na Tabela 3 e levando-se em consideração a diferença entre os volumes dos corpora de 1970 e de 2010.

O que mais chamou a nossa atenção, entretanto, foi o fato de as retomadas por pronomes nulos no PE, ao longo das décadas, se tornarem mais frequentes do que as retomadas por pronomes plenos. Em 1970, a preferência para retomar tópicos com traço [+humano] era dos pronomes plenos: 18 ocorrências de retomada por pronome pleno contra 11 de retomada por nulo. Esse quadro se inverteu na década de 2010: 2 retomadas por pronomes plenos contra 6 retomadas por nulos. Assim, o PE parece continuar reforçando a sua capacidade de realização do traço de pessoa através da morfologia verbal, dispensando o preenchimento do sujeito referencial, em oposição ao que ocorre no PB.

Duarte (1993, 1995, 2008), Duarte e Varejão (2013), Kato e Duarte (2014), entre outros, enquadram o PB como língua de sujeito nulo parcial - ou “partialpro-drop”. Línguas nessa condição normalmente se encontram em um estágio de transição entre o sujeito nulo e o sujeito preenchido. Processo semelhante teria acontecido com o francês, segundo Roberts (1993, p. 414-415) apud Duarte (2003, p. 13-14),

O francês não perdeu seus sujeitos nulos da noite para o dia (...). Houve um período de aproximadamente 150 anos durante os quais o francês conviveu com um sistema de sujeito nulo 'defectivo': um sistema que permitia sujeitos nulos apenas com certas pessoas e/ou certos contextos sintáticos.

Julgamos que as diferenças substanciais entre os sistemas de concordância do PB e do PE quanto ao fenômeno estudado assemelham a situação do PB à do francês e podem desencadear fenômenos morfossintáticos futuros que distanciem cada vez mais as duas gramáticas.

As operações sintáticas aqui estudadas aproximam o PB das línguas de sujeito preenchido e o PE das línguas de sujeito nulo. Nossos dados mostram que, enquanto o PB tende a preencher cada vez mais o sujeito, independente da condição semântica do referente, o PE tem recorrido com mais frequência ao sujeito nulo para retomar tópicos [+humanos], revelando manutenção na estabilidade do parâmetro pro-drop. Além disso, 
embora ambas as variedades possam apresentar construções com e sem sujeito preenchido, as condições sintáticas que levam ao preenchimento do sujeito em retomadas de tópicos são consideravelmente diferentes entre PB e PE. Assim, as diferenças estruturais subjacentes às ocorrências de cada variedade resultam de marcações diferentes do parâmetro do sujeito nulo. Enquanto o PE mantém o parâmetro marcado positivamente, o PB se encontra em um possível processo de transição rumo à marcação negativa do mesmo parâmetro.

\section{CONCLUSÕES}

Com este trabalho, observamos como se organizam, em cada variedade, as relações entre o tópico e a sua retomada em posição de sujeito nas construções de TPR e pudemos avaliar até que ponto as gramáticas do PB e do PE se aproximam ou se distanciam em sentenças envolvendo tópicos e sujeitos.

A priori, o que se percebeu foi o fortalecimento do sujeito preenchido por pronome em PB nas situações de retomada de tópico. Esse tipo de ocorrência cresceu significativamente entre 1970 e 2010, reforçando a hipótese sustentada pelos estudiosos brasileiros de que o PB vem perdendo a capacidade de realizar o traço de pessoa somente através da morfologia verbal, recorrendo à realização do pronome para tal. Dessa forma, compreendemos que, em PB, a posição Spec, TP é sempre projetada para fazer a checagem do traço D em construções de TPR.

No que se refere à relação entre o tópico e a sua retomada em posição de sujeito, o que se pode perceber é que as diferenças sintáticas entre PB e PE quanto às construções de tópico parecem ser motivadas por peculiaridades morfológicas de cada variedade. Diferentes propriedades morfológicas referentes aos procedimentos de concordância e checagem de traços geram diferentes operações sintáticas - e, portanto, repercussões nas estruturas das sentenças. Nas construções de TPR com retomada em posição de sujeito, percebemos que uma das consequências de PB e PE possuírem morfologias próprias foi a diferença na organização dos constituintes na estrutura sintática subjacente. Nesse sentido, os aspectos da língua estudados neste artigo nos levam a concordar com Costa (2010). O autor mostra que várias das características utilizadas para caracterizar o PB como uma língua orientada para o tópico também ocorrem no PE, inclusive o que ele chama de "ocorrência irrestrita de sujeitos duplos". O que se estabelece entre as duas variedades, então, não é um distanciamento decorrente de propriedades discursivas, como uma suposta orientação para discurso. Antes, verifica-se que, conforme Costa (2010, p. 125), "algumas das principais diferenças entre as duas variedades assentam no comportamento da concordância, o que indicará que a mudança sintática se baseia nas propriedades de Infl e não em aspectos macro-paramétricos”. 


\section{REFERÊNCIAS}

ARAÚJO, Edivalda Alves. As construções de tópico do português nos séculos XVIII e XIX. Tese de doutorado. Salvador: Programa de Pós-Graduação em Letras e Linguística da UFBA, 2006.

ARAÚJO, Edivalda Alves. Construções de Tópico. In: LUCCHESI, Dante; BAXTER, Alan; RIBEIRO, Ilza. (Org.). O Português Afro-Brasileiro. Salvador: Edufba, v. 1, 2009. p. 231-250.

AVELAR, Juanito; GALVES, Charlotte. Tópico e concordância em português brasileiro e português europeu. Textos selecionados - XXVI Encontro da Associação Portuguesa de Linguística. Lisboa: APL, 2011.

BARBOSA, Pilar. Ainda a questão dos sujeitos pré-verbais em PE: uma resposta a Costa. DELTA, PUC-SP, São Paulo, ano 22, n. 2, 2006. p. 345-402.

BARBOSA, Pilar. Null Subjects. Tese de doutorado. Cambridge: MITWPL, 1995.

BRAGA, Maria Luiza. Topicalizações, deslocamento à esquerda e discurso. Relatório de Pesquisa Apresentado ao CNPQ. Uberlândia, MG, 1987.

BRITO, Ana Maria; DUARTE, Inês; MATOS, Gabriela. Frases com tópicos marcados. In: MIRA MATEUS, M. H. et al. Gramática da língua portuguesa. 5.ed. rev. e aum. Lisboa: Caminho, 2003. p. 489-502

CHOMSKY, Noam. Derivation by phase. Cambridge: MITWPL, v. 18, 1999.

CHOMSKY, Noam. New horizons in the study of language and mind. Cambridge: Cambridge University Press, v. 20, 2001.

CYRINO, Sonia Maria Lazzarini; DUARTE, Maria Eugênia Lamoglia; KATO, Mary Aizawa. Visible subjects and invisible clitics in Brazilian Portuguese. In: KATO, Mary Aizawa; NEGRÃO, Esmeralda (Ed.) Brazilian Portuguese and the Null Subject Parameter. Frankfurt: Vervuert, 2000.

DUARTE, Maria Eugênia Lamoglia. Do Pronome Nulo ao Pronome Pleno: a trajetória do sujeito no português do Brasil. In: KATO, Mary Aizawa; ROBERTS, Ian. (org.). Português brasileiro: uma viagem diacrônica. 2. ed. Campinas: Editora da UNICAMP, 1996. p. 107-128.

DUARTE, Eugênia. Sujeito nulo/pleno e marcas de concordância. In: VOTRE, Sebastião; RONCARATI, Cláudia (org.). Anthony Julius Naro e a linguística no Brasil: uma homenagem acadêmica. Rio de Janeiro: 7Letras, 2008. p. 265-277.

DUARTE, Maria Eugênia Lamoglia; VAREJÃO, Filomena. Null subjects and agreement marks in European and Brazilian Portuguese. Journal of Portuguese Linguistics, Lisboa, ano 12, v.2, 2013. p. 101-123. 
FIGUEIREDO SILVA, Maria Cristina. A posição sujeito no português brasileiro: frases finitas e infinitivas. Campinas: Editora da UNICAMP, 1996.

GALVES, Charlotte. Ensaios sobre as gramáticas do português. Campinas: Editora da UNICAMP, 2001.

GALVES, Charlotte. O enfraquecimento da concordância no português brasileiro. In: KATO, Mary Aizawa; ROBERTS, Ian. (org.). Português brasileiro: uma viagem diacrônica. Campinas: Editora da UNICAMP, 1996. p. 387-408.

GALVES, Charlotte. Tópicos, sujeitos, pronomes e concordância no português brasileiro. In: Cadernos de Estudos Lingüísticos. Campinas: Editora da UNICAMP, n.34, jan/jun. 1998. p. 19-31.

KATO, Mary Aizawa. Strong pronouns, weak pronominals and the null subject parameter. In: PROBUS. Berlim: Mouton de Gruyter, n. 11, 1999. P. 1-37.

KATO, Mary Aizawa. Tópico e sujeito: duas categorias na sintaxe? Cadernos de Estudos Lingüisticos, Campinas, SP: Editora da UNICAMP, n. 17, 1989.

KATO, Mary Aizawa.; DUARTE, Maria Eugênia Lamoglia; CYRINO, Sônia Maria Lazarini; BERLICK, Rosane. Português brasileiro no fim do século XIX e na virada do milênio. In: CARDOSO, Suzana; MOTA, J., Jacyra Mota; MATOS E SILVA, R. V (Org.). Quinhentos anos de história linguística do Brasil. Salvador: Empresa Gráfica da Bahia/Funcultura/Governo da Bahia, 2006. p. 413-438.

LOPES, Célia R. dos S.; CUNHA, C. de S. Pronomes Pessoais: a pesquisa sociolinguística e a atualização da gramática. Trabalho apresentado no I Congresso Internacional da ABRALIN. Salvador: UFBA, 1994.

LOPES, Célia R. dos S. A inserção de 'a gente' no quadro pronominal do português. Frankfurt/Madri: Vervuert/Iberoamericana, vol. 18, 2003.

ORSINI, Mônica T.; VASCO, Sergio Leitão. Português do Brasil: língua de tópico e de sujeito. Diadorim - Revista de Estudos Linguísticos e Literários da Pós Graduação da UFRJ, Rio de Janeiro: UFRJ, Vol.2, p.83-98, 2007.

ORSINI, Mônica T.; PAULA, Mayara N. de. Sujeitos deslocados à esquerda e mudança paramétrica no PB, Revista do GELNE - Revista do Grupo de Estudos Linguísticos do Nordeste, UFPB, vol. 13, n 2, 2011, p. 107-127.

PAREDES SILVA, V. L. A distribuição dos pronomes de segunda pessoa do singular na fala carioca ao longo do século XX. II Congresso Nacional da Abralin (CD-rom), 2000.

PONTES, Eunice. O tópico no português do Brasil. Campinas: Pontes Editores, 1987.

RAPOSO, Eduardo. Towards a unification of topic constructions. UCSB. 1996. Texto inédito.s/r.

RIZZI, Luigi. Locality and left periphery. In: Structures and beyond. The cartography of syntactic structures. Oxford: Oxford University Press, 2004. p. 223-251. 
RIZZI, Luigi. The fine structure of the left periphery. In: Elements of grammar. Amsterdam: Springer, 1997. p. 281-337.

ROBERTS, Ian.; HOLMBERG, Anders. (Introduction: parameters in minimalist theory. In: BIBERAUER, Theresa; ROBERTS, Ian; HOLMBERG, Anders; SHEEHAN Michelle. (Org.). Parametric Variation: Null Subjects in Minimalist Theory. Cambridge: Cambridge University Press, 2010. p. 1-58.

SANTOS, Ângela Marina Bravin dos. O sujeito pronominal de $3^{a}$ pessoa no português culto do Rio de Janeiro: um estudo em tempo real. DELTA, PUC-SP, São Paulo, 2009.

Syntax Tree Generator. Utilizado para geração das imagens das árvores sintáticas presentes neste trabalho. Disponível em <http://mshang.ca/syntree/>. Acesso em: 22 dez 2016.

TARALLO, Fernando. Diagnosticando uma gramática brasileira: o português d'aquém e d'além-mar ao final do século XIX. In: ROBERTS, I.; KATO, M.A. (Org.). Português brasileiro: uma viagem diacrônica. Campinas: Editora da Unicamp, 1993. p. 9-106.

TARALLO, Fernando; DUARTE, Maria Eugênia Lamoglia. Processos de mudança linguística em progresso: a saliência vs. não saliência de variantes. Ilha do Desterro: A Journal of English Language, Literatures in English and Cultural Studies. Florianopolis: EDUFSC, v. 20, p. 44-58, 1988.

Recebido em: 17/05/2017

Aprovado em: 25/08/2017

Publicado em: 01/12/2017 